\title{
SELEÇÃO DE HÍBRIDOS DE SORGO GRANÍFERO CULTIVADOS NO VERÃO EM TRÊS LOCALIDADES
}

\author{
KARLA JORGE DA SILVA ${ }^{1}$, CICERO BESERRA DE MENEZES ${ }^{2}$, FLÁVIO DESSAUNE TARDIN², \\ BEATRIZ MARTI EMYGDIO ${ }^{4}$, VANDER FILLIPE DE SOUZA², \\ GERALDO AFONSO DE CARVALHO ${ }^{3}$ e MICHELE JORGE DA SILVA ${ }^{3}$
}

\author{
${ }^{1}$ UFSJ (Campus Sete Lagoas), Sete Lagoas, MG, Brasil, karla.js@hotmail.com \\ ${ }^{2}$ Embrapa Milho e Sorgo, Sete Lagoas, MG, Brasil, cicero.menezes@embrapa.br,vander_agro@hotmail.com, \\ flavio.tardin@embrapa.br \\ ${ }^{3}$ UFV,Viçosa,MG,Brasil,g.acjunior@gmail.com, michelejorge06@yahoo.com.br \\ ${ }^{4}$ Embrapa Clima Temperado, Pelotas, RS, Brasil, beatriz.emygdio@embrapa.br
}

Revista Brasileira de Milho e Sorgo, v.12, n.1, p. 44-53, 2013

\begin{abstract}
RESUMO - O sorgo granífero tem apresentado significativa expansão em área e em produtividade no Brasil nos últimos anos, em razão do aumento da demanda de grãos para alimentação animal. O melhoramento de plantas tem contribuído para o aumento de produtividade, com a oferta de novos híbridos adaptados às diversas áreas de produção. O presente trabalho teve o objetivo de selecionar aqueles mais produtivos e estáveis em cultivo de verão em três localidades. Os experimentos foram instalados em Sete Lagoas, MG, Nova Porteirinha, MG e Pelotas, RS. O delineamento experimental foi em blocos casualizados, com três repetições. Os híbridos comerciais BRS 310 e BRS 330 foram usados como testemunhas. Houve diferenças significativas entre os híbridos para as quatro características avaliadas, mostrando haver variabilidade entre os híbridos. A interação genótipos $\mathrm{x}$ ambientes foi significativa para índice de colheita de panículas e produtividade de grãos. A produtividade média das testemunhas nos três ambientes foi de $4,5 \mathrm{tha}^{-1}$, sendo que 11 híbridos foram estatisticamente superiores às mesmas. Os híbridos 1099030 e 1099048 apresentaram desempenho superior aos demais híbridos, com produtividade acima de $6,0 \mathrm{tha}^{-1}$, e ciclo de maturação mais precoce do que a testemunha mais produtiva: BRS 330.
\end{abstract}

Palavras-chave: Sorghum bicolor; seleção de híbridos; produtividade; interação genótipos x ambientes.

\section{SELECTION OF SORGHUM HYBRIDS CULTIVATED IN SUMMER IN THREE LOCATIONS}

\begin{abstract}
Cultivated area and yield of grain sorghum has increased considerably in Brazil in the last few years due to the increased demand of grains for animal feed. Plant breeding has contributed to productivity increase, providing new hybrids adapted to different production areas. The purpose of this work was to evaluate 25 hybrids in three environments. The trials were carried out in Sete Lagoas, MG, Pelotas, RS and Nova Porteirinha, MG. Hybrids were grown in a randomized complete block design with three replications. The hybrids BRS 310 and BRS 330 were used as check cultivars. The effect of hybrids was significant, showing variability among them. The interaction genotypes $\mathrm{x}$ environments for yield and panicle harvest index were significant, showing no coincidence between the performance of the hybrids at the different locations. Check cultivars yielded $4.5 \mathrm{t} \mathrm{ha}^{-1}$, while eleven hybrids were superior to them. The best hybrids were 1099030 and 1099048, with yield higher than 6.0 ton ha-1 and earlier maturity. Key words: Sorghum bicolor; hybrid selection; yield; interaction genotypes x environments.
\end{abstract}


O sorgo [Sorghum bicolor (L.) Moench] é o quinto cereal mais plantado no mundo, depois do trigo, do arroz, do milho e da cevada, sendo cultivado em várias regiões tropicais e subtropicais. No entanto, possui características adaptativas para cultivo em áreas marginais superiores a esses cereais. O sorgo é cultivado em 40 milhões de hectares em diversos países da África, da Ásia, da Oceania e das Américas, sendo os maiores produtores mundiais os Estados Unidos, a Índia e o México (FAO, 2009). O sorgo granífero apresenta amplo potencial para uso nos cultivos de safrinha, em que é possível mecanizar todas as práticas culturais da lavoura. Adicionalmente, essa cultura permite, ainda, uma maior amplitude da época de semeadura, possibilitando maior flexibilidade na implantação da cultura em safrinha (Pale et al. 2003).

O resultado obtido para a produção de sorgo granífero na safra brasileira de 2012 foi de aproximadamente 2 milhões de toneladas. A produtividade média nacional também subiu de 2.568 $\mathrm{kg} \mathrm{ha}^{-1}$ para $2.973 \mathrm{~kg} \mathrm{ha}^{-1}$, calculada para uma área explorada de 711 mil hectares (IBGE, 2012).

As regiões Centro-Oeste e Sudeste respondem por mais de $80 \%$ da produção nacional de sorgo, mas as regiões Sul e Nordeste também têm mostrado investimentos em pesquisa e divulgação dessa cultura. Como o Brasil apresenta grande diversidade em termos de condições climáticas, não se espera que o comportamento dos híbridos de sorgo seja equivalente em todas as regiões. O sorgo responde às mudanças ambientais, principalmente temperatura e comprimento do dia. Por ser originário de regiões quentes, é muito prejudicado por temperaturas baixas, que atrasam o ciclo da cultura. Na Região Sul, o sorgo é plantado na primavera e colhido no outono. No Brasil Central, a semeadura é feita em sucessão às culturas de verão, principalmente a soja. E, no Nordeste, ele é plantado na estação das chuvas. Uma característica comum a todas estas regiões de cultivo é o plantio de sequeiro (Teixeira, 2004).

A identificação de cultivares de sorgo adaptadas a cada região torna-se essencial à medida que a cultura se expande para plantio em diferentes épocas e regiões edafoclimáticas. $\mathrm{O}$ alto rendimento do sorgo está diretamente relacionado com a época de plantio, a escolha do híbrido e o manejo da cultura. Para o plantio, é importante que haja escalonamento dos diferentes híbridos dentro da faixa, ou seja, começar com plantio de híbridos mais tardios e finalizar com híbridos mais precoces. Os híbridos mais tardios, de forma geral e em condições ótimas de umidade e radiação solar, são mais produtivos do que os mais precoces. No entanto, estes híbridos não devem ser plantados no final da safra, devido à restrição hídrica no final do ciclo, principalmente em plantios de safrinha tardia. Nas semeaduras realizadas no final de fevereiro e início de março, o produtor deve optar por híbridos precoces, uma vez que a umidade do solo ainda está favorável para produção, pelo menos até o florescimento do híbrido.

O Brasil possui várias empresas com programas de melhoramento de sorgo granífero com diversas linhas de pesquisa, visando ao desenvolvimento de híbridos com alto potencial produtivo, de ciclo precoce e adaptados a diferentes regiões de plantio. Por isso, no presente trabalho, a produtividade de grãos e a precocidade de híbridos de sorgo granífero foram avaliadas em três regiões distintas, com objetivo de selecionar aqueles mais produtivos e estáveis em cultivo de verão. 


\section{Material e Métodos}

Foram avaliados 25 híbridos de sorgo granífero, sendo 23 experimentais e duas testemunhas comerciais (BRS 310 e BRS 330). Os experimentos foram instalados em Nova Porteirinha, MG, em Pelotas, RS e em Sete Lagoas, MG.

Nova Porteirinha está localizada na Região Norte de Minas Gerais, $15^{\circ} 48^{\prime} 10^{\prime}$ 'de latitude Sul e $43^{\circ} 18^{\prime} 03^{\prime \prime}$ de longitude Oeste, apresenta clima semiárido com chuvas irregulares. O município de Pelotas localiza-se no Sudeste do Rio Grande do Sul, $31^{\circ} 46^{\prime}$ 19 " de latitude Sul e $52^{\circ} 20^{\prime} 33^{\prime \prime}$ de longitude Oeste. A região possui clima temperado úmido, com precipitação pluviométrica anual média de $1.366,9 \mathrm{~mm}$ e temperatura média de $17,8^{\circ} \mathrm{C}$. Sete Lagoas se encontra na região central de Minas Gerais, 19² $27^{\prime}$ 57' de latitude Sul e $44^{\circ} 14^{\prime}$ '49" de longitude Oeste, apresenta clima tropical de altitude, com verões quentes e chuvosos e invernos secos. A estação chuvosa ocorre de outubro a março e a estiagem de maio a agosto.

Os experimentos foram instalados no delineamento de blocos casualizados, com três repetições e parcelas de 4 linhas de $5 \mathrm{~m}$ de comprimento, sendo as duas linhas centrais utilizadas como parcela útil.

As semeaduras fora realizadas em dezembro de 2010, sendo que a colheita em Sete Lagoas foi em abril de 2011 e em Pelotas e Nova Porteirinha em maio de 2011. As adubações de plantio e de cobertura foram realizadas com base nas análises de solo e os tratos culturais e fitossanitários ocorreram de acordo com a necessidade da cultura e de cada região.

Foram avaliadas as características: florescimento (número de dias decorridos desde o plantio até o florescimento de $50 \%$ das plantas da unidade experimental); altura de plantas (altura média, em metros, de seis plantas competitivas, medidas do nível do solo até o ápice da panícula); peso de panículas; produção de grãos (peso de grãos da unidade experimental, corrigido para umidade de $13 \%$ e transformado para $\mathrm{tha}^{-1}$ ); e índice de colheita de panículas (ICP - relação entre o peso de grãos e o peso de panículas). As características ICP e produção de grãos foram avaliadas nos três ambientes, enquanto florescimento e altura de plantas foram avaliados em Pelotas e em Sete Lagoas.

Inicialmente, os experimentos foram analisados separadamente de acordo com o modelo estatístico $Y_{i j}=\mu+g_{i}+b_{j}+e_{i j}$, em que: $Y_{i j}=$ observação feita na parcela do i-ésimo tratamento no $\mathrm{j}$ -ésimo bloco; $\mu$ = média geral; $\mathrm{g}_{\mathrm{i}}=$ efeito do $\mathrm{i}$-ésimo híbrido; $b_{j}=$ efeito do j-ésimo bloco; $\mathrm{e}_{\mathrm{ij}}=$ efeito dos fatores não controlados na parcela que recebeu o i-ésimo híbrido no j-ésimo bloco. Após análise individual, foi realizada análise de variância conjunta, de acordo com o modelo estatístico $\mathrm{Y}_{\mathrm{ijk}}=\mu+\mathrm{g}_{\mathrm{i}}+\mathrm{a}_{\mathrm{j}}+$ $\mathrm{ga}_{\mathrm{ij}}+\mathrm{b}_{\mathrm{k}} / \mathrm{a}_{\mathrm{j}}+\mathrm{e}_{\mathrm{ijk}}$, em que: $\mathrm{Y}_{\mathrm{ijk}}=$ observação feita na parcela do i-ésimo tratamento no j-ésimo bloco; $\mu=$ média geral; $g_{i}=$ efeito do i-ésimo híbrido; $a_{j}=$ efeito do j-ésimo ambiente; ga $_{\mathrm{ij}}=$ efeito de interação do i-ésimo híbrido com o j-ésimo ambiente; $b_{k} / a_{j}=$ efeito do k-ésimo bloco dentro do j-ésimo ambiente; $\mathrm{e}_{\mathrm{ijk}}=$ efeito dos fatores não controlados na parcela que recebeu o i-ésimo híbrido no j-ésimo ambiente dentro do k-ésimo bloco. Para determinação da adaptabilidade e da estabilidade, foi avaliada a característica produção de grãos, utilizando a metodologia de Lin \& Binns (1988). Os dados obtidos foram analisados utilizando-se os recursos computacionais do programa Genes (Cruz, 2006).

O teste de Scott-Knott, com 5\% de probabilidade, foi utilizado para comparação e agrupamento das médias dos híbridos avaliados, com auxílio do software Sisvar (Ferreira, 2008). 


\section{Resultados e Discussão}

Os coeficientes de variação (CVs) foram baixos para todas as características, exceto produção de grãos, que foi de nível intermediário. Estes CVs estão dentro de limites encontrados por outros autores (Silva et al., 2009; Almeida Filho et al., 2010; Silva et al., 2010) para a cultura do sorgo granífero. De forma geral, a produtividade de grãos é a característica mais influenciada pelo ambiente.

Houve diferenças significativas para a fonte de variação híbridos, ao nível de $1 \%$ de probabilidade para todas as características avaliadas, indicando a existência de variabilidade entre eles, o que possibilita a seleção de híbridos superiores. Para as fontes de variação ambientes e interação híbridos x ambientes, diferenças significativas foram observadas para ICP e para produção de grãos, indicando que os ambientes foram distintos um do outro e que o desempenho dos híbridos não foi coincidente nos três ambientes (Tabela 1). A significância da interação híbridos por ambientes para produção de grãos em sorgo já foi demonstrada por outros pesquisadores. Almeida Filho et al. (2010) avaliaram 25 híbridos de sorgo granífero em Acreúna, GO, Itumbiara, GO, Sete Lagoas, MG, Vilhena, RO e Teresina, PI e concluíram que o rendimento de grãos foi bastante afetado pelo ambiente. Mesmo em ambientes próximos, dentro da mesma região produtora de sorgo, podem ser encontradas interações híbridos por locais, como foi demonstrado por Silva et al. (2009), que avaliaram a interação entre cultivares de sorgo granífero em três ambientes bem próximos, no Sudoeste goiano (Montividiu, Rio Verde e Santa Helena).

Para as características florescimento e altura de plantas, não houve diferenças significativas para as fontes de variação ambientes e interação híbridos x ambientes, mostrando que, para essa época de plantio, os ambientes de Sete Lagoas, Pelotas e Nova Porteirinha não foram diferentes entre si.

$\mathrm{Na}$ Tabela 2, estão apresentadas as médias para as características índice de colheita (ICP), produção de grãos e altura de planta. Devido à significância da interação híbridos x ambientes para as duas primeiras características, as médias são

TABELA 1. Resumo das análises de variância conjuntas para índice de colheita de panículas (ICP), produção de grãos ( $\left.\mathrm{t} \mathrm{ha}^{-1}\right)$, florescimento (dias) e altura de plantas (cm), 2011.

\begin{tabular}{lcccccc}
\hline \multirow{2}{*}{ FV } & GL & \multicolumn{2}{c}{ Quadrados Médios } & & \multicolumn{2}{c}{ Quadrados Médios } \\
\cline { 3 - 4 } & & ICP & Produção de grãos & & Florescimento & Altura de plantas \\
\hline Blocos & 2 & 0,002956 & 0,9283 & 2 & 1.568 .567 & 325.673 \\
Híbrido (H) & 24 & $0,00629^{* *}$ & $3,1862^{* *}$ & 24 & $113,9739^{* *}$ & $811.0543^{* *}$ \\
Ambientes (A) & 2 & $0,71978^{* *}$ & $159,4972^{* *}$ & 1 & $0,4267^{\text {ns }}$ & $134.6161^{\text {ns }}$ \\
H x A & 48 & $0,00551^{* *}$ & $1,3871^{* *}$ & 24 & $39.0794^{\text {ns }}$ & $78.7502^{\text {ns }}$ \\
Resíduo & 144 & 0,0031 & 0,8019 & 96 & 399.075 & 82,0377 \\
\hline Média & & 0,6963 & 5,15 & & 66,75 & 105,21 \\
\hline CV $(\%)$ & 7,98 & 17,49 & & 9,37 & 10,26 \\
\hline
\end{tabular}

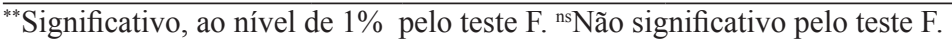


TABELA 2. Médias para as características índice de colheita de panículas (ICP), produção de grãos e altura de plantas, de 25 híbridos de sorgo granífero, avaliadas em Sete Lagoas, MG (SL), Pelotas, RS (PLT) e Nova Porterinha, MG (NAPA), 2011.

\begin{tabular}{|c|c|c|c|c|c|c|c|c|c|}
\hline \multirow{2}{*}{ Híbridos } & \multicolumn{4}{|c|}{$\mathrm{ICP}^{1}$} & \multicolumn{4}{|c|}{ Produção de grãos $\left(\mathrm{t} \mathrm{ha}^{-1}\right)^{1}$} & \multirow{2}{*}{$\begin{array}{c}\text { Altura de } \\
\text { plantas }(\mathrm{cm})\end{array}$} \\
\hline & SL & PLT & NAPA & Média & SL & PLT & NAPA & Média & \\
\hline 1099030 & $0,60 \mathrm{~A}$ & $0,73 \mathrm{~A}$ & $0,83 \mathrm{~A}$ & $0,72 \mathrm{~A}$ & $4,70 \mathrm{~A}$ & $6,20 \mathrm{~A}$ & $8,57 \mathrm{~A}$ & $6,49 \mathrm{~A}$ & $124,17 \mathrm{~B}$ \\
\hline 1099048 & $0,66 \mathrm{~A}$ & $0,67 \mathrm{~A}$ & $0,84 \mathrm{~A}$ & $0,72 \mathrm{~A}$ & $5,43 \mathrm{~A}$ & $4,72 \mathrm{~A}$ & $8,92 \mathrm{~A}$ & $6,36 \mathrm{~A}$ & $117,38 \mathrm{~B}$ \\
\hline 1099012 & $0,67 \mathrm{~A}$ & $0,73 \mathrm{~A}$ & $0,82 \mathrm{~A}$ & $0,74 \mathrm{~A}$ & $5,03 \mathrm{~A}$ & $4,52 \mathrm{~A}$ & $8,07 \mathrm{~A}$ & $5,87 \mathrm{~B}$ & $102,72 \mathrm{C}$ \\
\hline 1099037 & $0,61 \mathrm{~A}$ & $0,67 \mathrm{~A}$ & $0,78 \mathrm{~A}$ & $0,69 \mathrm{~B}$ & $4,62 \mathrm{~A}$ & $4,61 \mathrm{~A}$ & 7,99 A & $5,74 \mathrm{~B}$ & $109,13 \mathrm{C}$ \\
\hline 1099020 & $0,65 \mathrm{~A}$ & $0,72 \mathrm{~A}$ & $0,78 \mathrm{~A}$ & $0,72 \mathrm{~A}$ & $4,39 \mathrm{~A}$ & $5,35 \mathrm{~A}$ & $6,84 \mathrm{~A}$ & $5,53 \mathrm{~B}$ & $135,62 \mathrm{~A}$ \\
\hline 1099018 & $0,51 \mathrm{C}$ & $0,74 \mathrm{~A}$ & $0,80 \mathrm{~A}$ & $0,68 \mathrm{~B}$ & $3,26 \mathrm{~B}$ & $5,28 \mathrm{~A}$ & 7,95 A & $5,50 \mathrm{~B}$ & $103,17 \mathrm{C}$ \\
\hline 1099036 & $0,58 \mathrm{~B}$ & $0,66 \mathrm{~A}$ & $0,80 \mathrm{~A}$ & $0,68 \mathrm{~B}$ & $5,42 \mathrm{~A}$ & $3,86 \mathrm{~A}$ & $7,11 \mathrm{~A}$ & $5,46 \mathrm{~B}$ & $96,67 \mathrm{D}$ \\
\hline 1099039 & $0,65 \mathrm{~A}$ & $0,69 \mathrm{~A}$ & $0,83 \mathrm{~A}$ & $0,72 \mathrm{~A}$ & $4,91 \mathrm{~A}$ & $4,14 \mathrm{~A}$ & $7,30 \mathrm{~A}$ & $5,45 \mathrm{~B}$ & $98,12 \mathrm{D}$ \\
\hline 1099043 & $0,65 \mathrm{~A}$ & $0,76 \mathrm{~A}$ & $0,80 \mathrm{~A}$ & $0,74 \mathrm{~A}$ & $5,29 \mathrm{~A}$ & $4,48 \mathrm{~A}$ & $6,53 \mathrm{~B}$ & $5,43 \mathrm{~B}$ & $101,62 \mathrm{C}$ \\
\hline 1099035 & $0,58 \mathrm{~B}$ & $0,65 \mathrm{~A}$ & $0,82 \mathrm{~A}$ & $0,68 \mathrm{~B}$ & $4,22 \mathrm{~B}$ & $4,34 \mathrm{~A}$ & 7,61 A & $5,39 \mathrm{~B}$ & $107,50 \mathrm{C}$ \\
\hline 1099017 & $0,55 \mathrm{~B}$ & $0,74 \mathrm{~A}$ & $0,81 \mathrm{~A}$ & $0,70 \mathrm{~A}$ & $3,77 \mathrm{~B}$ & $4,96 \mathrm{~A}$ & 7,34 A & $5,36 \mathrm{~B}$ & $104,63 \mathrm{C}$ \\
\hline 1099019 & $0,53 \mathrm{~B}$ & $0,69 \mathrm{~A}$ & $0,78 \mathrm{~A}$ & $0,67 \mathrm{~B}$ & $3,38 \mathrm{~B}$ & $4,77 \mathrm{~A}$ & $7,38 \mathrm{~A}$ & $5,18 \mathrm{C}$ & $121,47 \mathrm{~B}$ \\
\hline 1099007 & $0,62 \mathrm{~A}$ & $0,64 \mathrm{~A}$ & $0,82 \mathrm{~A}$ & $0,69 \mathrm{~B}$ & $4,97 \mathrm{~A}$ & $4,19 \mathrm{~A}$ & $6,30 \mathrm{~B}$ & $5,15 \mathrm{C}$ & $98,30 \mathrm{D}$ \\
\hline 1099053 & $0,48 \mathrm{C}$ & $0,66 \mathrm{~A}$ & $0,75 \mathrm{~A}$ & $0,63 \mathrm{~B}$ & $3,51 \mathrm{~B}$ & $4,75 \mathrm{~A}$ & $6,67 \mathrm{~B}$ & $4,98 \mathrm{C}$ & $117,53 \mathrm{~B}$ \\
\hline 1099016 & $0,67 \mathrm{~A}$ & $0,69 \mathrm{~A}$ & $0,81 \mathrm{~A}$ & $0,73 \mathrm{~A}$ & $4,07 \mathrm{~B}$ & $4,23 \mathrm{~A}$ & $6,60 \mathrm{~B}$ & $4,96 \mathrm{C}$ & $108,03 \mathrm{~B}$ \\
\hline BRS 330 & $0,56 \mathrm{~B}$ & $0,67 \mathrm{~A}$ & $0,76 \mathrm{~A}$ & $0,66 \mathrm{~B}$ & $3,91 \mathrm{~B}$ & $3,68 \mathrm{~A}$ & $6,92 \mathrm{~A}$ & $4,84 \mathrm{C}$ & $104,30 \mathrm{C}$ \\
\hline 1099010 & $0,65 \mathrm{~A}$ & $0,67 \mathrm{~A}$ & $0,79 \mathrm{~A}$ & $0,70 \mathrm{~A}$ & $4,72 \mathrm{~A}$ & $3,21 \mathrm{~A}$ & $6,43 \mathrm{~B}$ & $4,79 \mathrm{C}$ & $77,53 \mathrm{E}$ \\
\hline 1099025 & $0,69 \mathrm{~A}$ & $0,71 \mathrm{~A}$ & $0,78 \mathrm{~A}$ & $0,73 \mathrm{~A}$ & $4,67 \mathrm{~A}$ & $4,16 \mathrm{~A}$ & $5,46 \mathrm{~B}$ & $4,76 \mathrm{C}$ & $103,97 \mathrm{C}$ \\
\hline 1099029 & $0,64 \mathrm{~A}$ & $0,64 \mathrm{~A}$ & $0,77 \mathrm{~A}$ & $0,68 \mathrm{~B}$ & $3,58 \mathrm{~B}$ & $3,57 \mathrm{~A}$ & $7,13 \mathrm{~A}$ & $4,76 \mathrm{C}$ & $94,78 \mathrm{D}$ \\
\hline 1099008 & $0,64 \mathrm{~A}$ & $0,65 \mathrm{~A}$ & $0,79 \mathrm{~A}$ & $0,69 \mathrm{~B}$ & $3,91 \mathrm{~B}$ & $4,56 \mathrm{~A}$ & $5,59 \mathrm{~B}$ & $4,69 \mathrm{C}$ & $107,33 \mathrm{C}$ \\
\hline 1099028 & $0,59 \mathrm{~B}$ & $0,76 \mathrm{~A}$ & $0,79 \mathrm{~A}$ & $0,71 \mathrm{~A}$ & $3,49 \mathrm{~B}$ & $4,38 \mathrm{~A}$ & $6,16 \mathrm{~B}$ & $4,68 \mathrm{C}$ & $94,33 \mathrm{D}$ \\
\hline 1099034 & $0,62 \mathrm{~A}$ & $0,69 \mathrm{~A}$ & $0,76 \mathrm{~A}$ & $0,69 \mathrm{~B}$ & $3,82 \mathrm{~B}$ & $4,59 \mathrm{~A}$ & $5,43 \mathrm{~B}$ & $4,61 \mathrm{C}$ & $104,38 \mathrm{C}$ \\
\hline 1099011 & $0,45 \mathrm{C}$ & $0,72 \mathrm{~A}$ & $0,83 \mathrm{~A}$ & $0,67 \mathrm{~B}$ & $3,68 \mathrm{~B}$ & $4,37 \mathrm{~A}$ & $5,27 \mathrm{~B}$ & $4,44 \mathrm{C}$ & $93,08 \mathrm{D}$ \\
\hline 307541 & $0,60 \mathrm{~A}$ & $0,67 \mathrm{~A}$ & $0,77 \mathrm{~A}$ & $0,68 \mathrm{~B}$ & $3,52 \mathrm{~B}$ & $3,36 \mathrm{~A}$ & $6,00 \mathrm{~B}$ & $4,29 \mathrm{C}$ & $100,30 \mathrm{C}$ \\
\hline BRS 310 & $0,55 \mathrm{~B}$ & $0,67 \mathrm{~A}$ & $0,80 \mathrm{~A}$ & $0,67 \mathrm{~B}$ & $3,62 \mathrm{~B}$ & $3,33 \mathrm{~A}$ & $5,23 \mathrm{~B}$ & $4,06 \mathrm{C}$ & $104,25 \mathrm{C}$ \\
\hline Média & 0,62 & 0,69 & 0,81 & 0,70 & 4,24 & 4,38 & 6,83 & 5,15 & 105,21 \\
\hline
\end{tabular}

${ }^{1}$ Médias seguidas de mesma letra, maiúscula na coluna, não diferem entre si $(\mathrm{p}<0,05)$, pelo teste de Scott-Knott. 
apresentadas por ambiente individualmente. Para índice de colheita, considerando as médias dos três ambientes, o teste de média agrupou os híbridos em dois grupos. Já em Sete Lagoas, o teste de média agrupou os híbridos em três grupos. Em Pelotas e em Nova Porteirinha, o teste de média não foi significativo. Onze híbridos apresentaram índices de colheita estatisticamente superiores às testemunhas comerciais $(1099010,1099012,1099016$, 1099017, 1099020, 1099025, 1099028, 1099030, 1099039, 1099043 e 1099048), mostrando a possibilidade da seleção de híbridos superiores aos plantados atualmente. O índice de colheita de grãos é muito utilizado no melhoramento para medir a relação de produção de grãos e peso de panículas, dando ideia do rendimento relativo de grãos, pois muitas vezes a planta tem um ótimo desenvolvimento, o que é normal na safrinha, e no final do ciclo ocorre um veranico, prejudicando a produção de grãos, principalmente reduzindo peso e número de grãos. Portanto, os híbridos com maior índice de colheita costumam suportar maiores estresses após o florescimento. Em Pelotas e em Sete Lagoas, os híbridos apresentaram menores índices de colheita, o que refletiu na produção de grãos quando comparada à de Nova Porteirinha.

A média de produtividade dos híbridos foi de 5,15 t ha-1, a qual está acima da média nacional, que é de 2,9 t ha-1. Esta elevada média pode estar correlacionada com as épocas de plantio dos ensaios, que foram semeados na época das chuvas (dezembro a maio). No Sul do Brasil e no Norte de Minas, o sorgo é plantado no verão, época em geral, de maior pluviosidade e, portanto, menor estresse hídrico.

As maiores produtividades foram obtidas no ensaio de Nova Porteirinha $\left(6,83 \mathrm{t} \mathrm{ha}^{-1}\right)$, seguidas pelos ensaios de Pelotas e de Sete Lagoas, com, respectivamente, 4,38 e 4,24 $\mathrm{t} \mathrm{ha}^{-1}$. As duas testemunhas comerciais, BRS 310 e BRS 330, apresentaram produtividades médias de 4,06 e 4,84 $\mathrm{t} \mathrm{ha}^{-1}$, respectivamente, não diferindo estatisticamente uma da outra, mas diferindo de vários híbridos experimentais.

Não houve diferenças significativas entre os híbridos em Pelotas, pelo teste de Teste ScottKnott. Já para Sete Lagoas, para Nova Porteirinha e na média geral, houve diferenças significativas. Nos ambientes em que houve significância do teste de médias, o híbrido BRS 310 foi sempre classificado no grupo de menor produtividade. O BRS 330 foi classificado no grupo de maior produtividade em Nova Porteirinha, mas foi superado por vários híbridos em Sete Lagoas e na média geral.

Considerando as médias dos três ambientes, 11 híbridos apresentaram produtividades superiores às duas testemunhas. Pelo teste de agrupamento de médias, para cada ambiente individualmente, sete híbridos foram classificados entre os mais produtivos nos três ambientes (1099012, 1099020, 1099030, 1099036, 1099037, 1099039 e 1099048). Estes híbridos são candidatos promissores e entrarão nos ensaios de VCU (Valor de Cultivo e Uso) para fins de registros junto ao Ministério da Agricultura, Pecuária e Abastecimento.

Todos os híbridos avaliados apresentaram florescimento dentro de níveis aceitáveis para o mercado nacional, variando de 57 a 75 dias. O teste de média agrupou os híbridos em dois grupos de florescimento, sendo um grupo de híbridos médios (abaixo de 65 dias) e outro de híbridos tardios (acima de 65 dias).

Os híbridos BRS 310 e BRS 330 foram classificados como médio e tardio, respectivamente. 


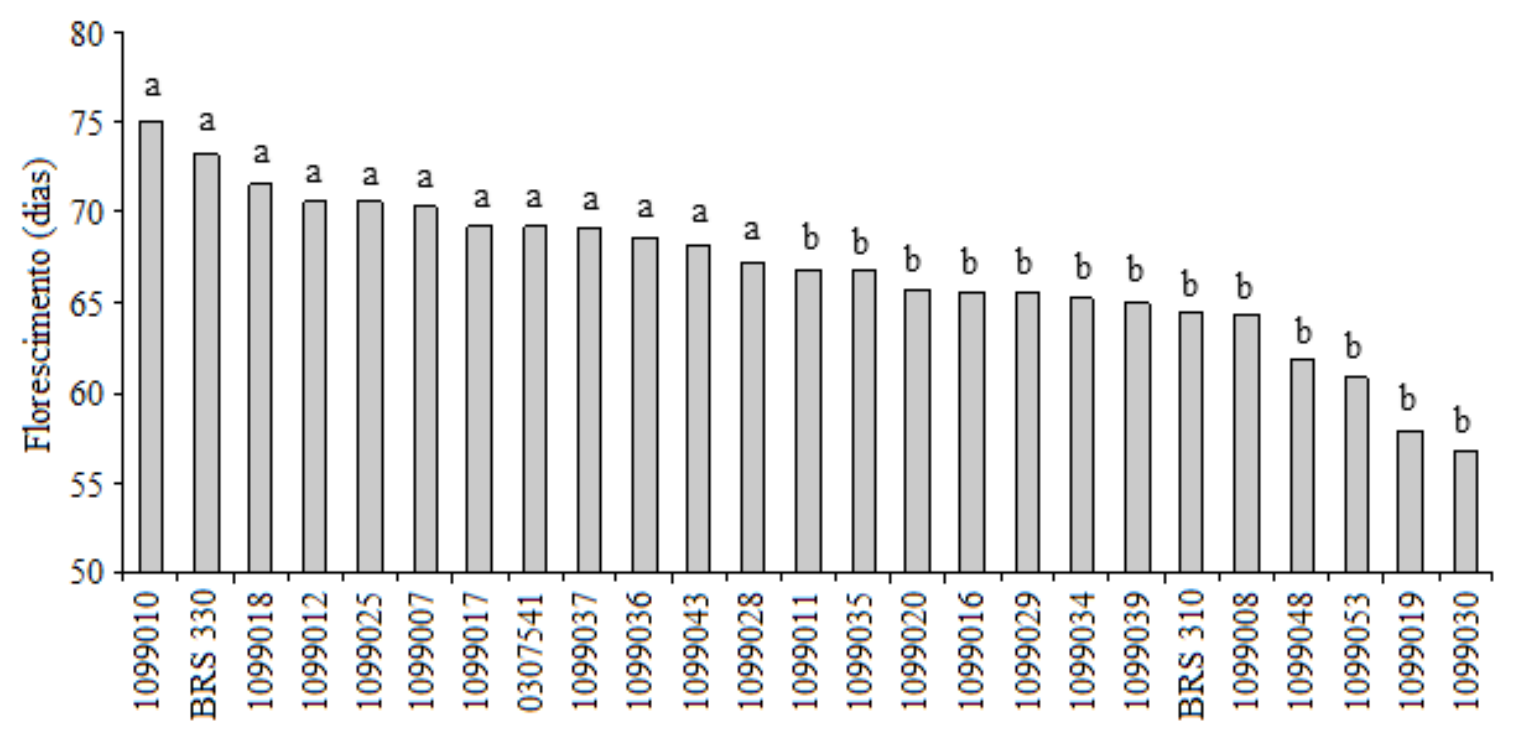

Hibridos

FIGURA 1. Médias de florescimento (dias) de 25 híbridos de sorgo granífero avaliados em três ambientes em cultivo de verão. Médias seguidas da mesma letra não diferem estatisticamente entre si pelo teste de ScottKnott ao nível de 5\% de probabilidade.

Dos 11 híbridos mais produtivos, considerando a média dos três ambientes, cinco possuem ciclos médios de maturação (1099020, 1099030, 1099035 , 1099039, 1099048,) e seis possuem ciclo tardio (1099018, 1099012, 1099017, 1099036, 1099037 e 1099043) (Tabela 2 e Figura 1).

O florescimento das plantas está relacionado com o ciclo de maturação dos grãos, o qual é altamente correlacionado com produção, ou seja, híbridos mais tardios apresentam produtividades maiores quando comparados a híbridos de ciclo mais precoce, devido ao maior tempo que a planta possui para acúmulo de fotoassimilados. O produtor de sorgo granífero inicia a safra com plantio de híbridos mais tardios (com florescimento acima de 70 dias após semeadura) e finaliza com híbridos mais precoces (abaixo de 60 dias da semeadura ao florescimento).

Outra característica importante para híbridos de sorgo é a altura de plantas, pois ela está

TABELA 3. Médias de produção de grãos $\left(\mathrm{t} \mathrm{ha}^{-1}\right)$, índices ambientais e classificação dos três ambientes, de 25 híbridos de sorgo granífero, 2011.

\begin{tabular}{cccc}
\hline Ambiente & Média & Índice & Classe \\
\hline Sete Lagoas, MG & 42.353 & $-0,9155$ & Desfavorável \\
Pelotas, RS & 43.846 & $-0,7662$ & Desfavorável \\
Nova Porteirinha, MG & 68.325 & 16.817 & Favorável \\
\hline
\end{tabular}


TABELA 4. Estimativas dos parâmetros de adaptabilidade e estabilidade de 25 híbridos de sorgo granífero, para produção de grãos em t ha-1 ${ }^{-1}$ com base na metodologia de Lin \& Binn (1988).

\begin{tabular}{|c|c|c|c|}
\hline \multirow{2}{*}{ Híbridos } & \multicolumn{3}{|c|}{ Lin \& Binns (1988) } \\
\hline & $\mathrm{Pi}^{1}$ Geral & $\mathrm{Pi}^{1}$ Favorável & $\mathrm{Pi}^{1}$ Desfavorável \\
\hline 1099030 & 0,1113 & 0,0630 & 0,1354 \\
\hline 1099048 & 0,3684 & 0,0000 & 0,5525 \\
\hline 1099012 & 0,6225 & 0,3632 & 0,7521 \\
\hline 1099037 & 0,6796 & 0,4321 & 0,8033 \\
\hline 1099020 & 10.197 & 21.549 & 0,4522 \\
\hline 1099018 & 10.890 & 0,4708 & 13.981 \\
\hline 1099035 & 11.079 & 0,8524 & 12.356 \\
\hline 1099017 & 11.331 & 12.493 & 10.750 \\
\hline 1099039 & 11.948 & 13.117 & 11.363 \\
\hline 1099019 & 14.411 & 11.868 & 15.682 \\
\hline 1099043 & 14.490 & 28.553 & 0,7458 \\
\hline 1099036 & 14.610 & 16.326 & 13.752 \\
\hline 1099053 & 18.124 & 25.313 & 14.530 \\
\hline 1099007 & 18.540 & 34.270 & 10.675 \\
\hline 1099016 & 18.600 & 26.935 & 14.432 \\
\hline BRS 330 & 21.131 & 20.033 & 21.680 \\
\hline 1099029 & 22.599 & 15.973 & 25.913 \\
\hline 1099028 & 24.576 & 38.217 & 17.755 \\
\hline 1099010 & 26.097 & 31.001 & 23.646 \\
\hline 1099008 & 26.832 & 55.378 & 12.560 \\
\hline 1099025 & 27.875 & 59.743 & 11.941 \\
\hline 1099034 & 28.996 & 61.052 & 12.969 \\
\hline 1099011 & 32.900 & 66.625 & 16.037 \\
\hline 307541 & 33.778 & 42.690 & 29.322 \\
\hline BRS 310 & 42.004 & 68.253 & 28.879 \\
\hline
\end{tabular}

${ }^{1} \mathrm{Pi}$ - Estimativa da estabilidade e adaptabilidade do cultivar $\mathrm{i}$. 
positivamente correlacionada com produtividade de grãos. No entanto, plantas altas tendem a ser suscetíveis ao acamamento, devendo, então, o híbrido ter uma altura adequada, de forma a produzir bem e não acamar até a colheita dos grãos.

A média da altura de plantas dos dois ambientes avaliados foi de $105 \mathrm{~cm}$, sendo, portanto, estes híbridos considerados baixos. Dos 11 híbridos mais produtivos, três apresentam alturas médias $(1099020,1099030$ e 1099048) e oito a porte baixo (1099012, 1099017, 1099018, 1099035, 1099036, 1099037, 1099039 e 1099043). Os híbridos BRS 310 e BRS 330 são considerados de porte baixo (Tabela 2).

Para a análise de adaptabilidade e da estabilidade dos híbridos de sorgo granífero, foi realizada a estimativa dos índices ambientais para a produtividade de grãos apresentados na Tabela 3 .

A variação de rendimento verificada entre ambientes evidencia a instabilidade nas condições climáticas durante o período estudado. O índice ambiental é a diferença entre a média geral do ambiente e a média geral de todos os ambientes. Nova Porteirinha foi classificado como ambiente favorável, ao passo que Sete Lagoas e Pelotas foram classificadas como tendo ambientes desfavoráveis.

O sorgo é plantado como cultura de sequeiro, sem irrigação suplementar. Durante os ensaios em Nova Porteirinha e em Sete Lagoas, a precipitação foi muito irregular. Em Nova Porteirinha, foram realizadas duas irrigações suplementares no mês de fevereiro, o que pode explicar o melhor desempenho dos híbridos neste local, uma vez que, nos outros meses, a precipitação foi maior do que em Sete Lagoas e em Pelotas. Já em Pelotas a precipitação, apesar de regular, foi muito limitada para a cultura.
Na Tabela 4, estão apresentados os valores de Pi geral, Pifav para os ambientes favoráveis e Pidesfav para os ambientes desfavoráveis dos 25 híbridos de sorgo granífero. Os híbridos comerciais BRS 310 e BRS 330 não apresentaram boa estabilidade, sendo superados por vários híbridos experimentais.

Comparando somente os dois híbridos comerciais, o BRS 330 foi mais estável do que o BRS 310. Os híbridos 1099030, 1099048, 1099012 e 1099037 tiveram as menores estimativas de Pig, Pifav e Pidesfav, mostrando serem híbridos estáveis para produção.

Corroborando com a significância da interação genótipos $\mathrm{x}$ ambientes, alguns híbridos apresentaram maior estabilidade nos ambientes desfavoráveis, como por exemplo, 1099020 e 1099043, ao passo que outros foram mais estáveis no ambiente favorável, como 1099018 e 1099035.

\section{Conclusões}

Os ensaios possibilitaram a seleção de híbridos de sorgo produtivos e estáveis, com ciclos mais precoces do que as testemunhas.

Os híbridos experimentais 1099030, 1099048, 1099012 e 1099037 superaram as testemunhas em todos os ambientes testados, mostrando produtividades altas e estáveis, elevados índices de colheita de grãos, sendo os dois primeiros de ciclo médio e os dois últimos de ciclo tardio.

\section{Agradecimentos}

À Embrapa Milho e Sorgo e à Fundação de Amparo à Pesquisa do Estado de Minas Gerais (Fapemig), pelo apoio financeiro ao projeto. 


\section{Referências}

ALMEIDA FILHO, J. E.; TARDIN, F. D.; SOUZA, S. A.; GODINHO, V. P.; CARDOSO, M. J. Desempenho agronômico e estabilidade fenotípica de híbridos de sorgo granífero. Revista Brasileira de Milho e Sorgo, Sete Lagoas, v. 9, p. 51-64, 2010.

CRUZ, C. D. Programa Genes - Estatística Experimental e Matrizes. Viçosa, MG: UFV, 2006.

FAO. FAOSTAT Production crops. Rome, 2009. Disponivel em: < http://faostat.fao.org/site/567/ DesktopDefault.aspx?PageID $=567$ \#ancor $>$ Acesso em: 20 nov. 2011.

FERREIRA, D. F. SISVAR: um programa para análises e ensino de estatística. Revista Symposium, Lavras, v. 6, p. 36-41, 2008.

IBGE. Estatística da Produção Agrícola, Rio de Janeiro, 1-94. Nov. 2012.

LIN, C. S.; BINNS, M. R. A method of analyzing cultivar $\mathrm{x}$ location $\mathrm{x}$ year experiments: a new stability parameter. Theoretical and Applied Genetics, New York, v. 76, p. 425-430, 1988
PALE, S.; MASON, S. C.; GALUSHA T. D. Planting time for early-season pearl millet and grain sorghum in Nebraska. Agronomy Journal, Madison, v. 95, p. 1047-1053, 2003.

SILVA, R. N. O.; ARNHOLD, E; ARAÚJO, B. L.; OLIVEIRA, G. H. F.; COSTA, J. R. S.; OLIVEIRA JUNIOR, E. A.; LIMA, C. F. Comportamento agronômico de cultivares de sorgo granífero avaliados em safrinha. Revista Trópica - Ciências Agrárias e Biológicas, São Luiz, v. 4, p.39-43, 2010 .

SILVA, A. G.; BARROS, A. S.; SILVA, L. H. C. P.; MORAES, E. B.; PIRES, R.; TEIXEIRA, I. R. Avaliação de cultivares de sorgo granífero na safrinha no sudoeste do estado de Goiás. Pesquisa Agropecuária Tropical, Goiânia, v. 39, p. 168174, 2009.

TEIXEIRA, P. E. G.; TEIXEIRA, P. P. M. Potencial nutritivo da silagem de sorgo. In: WORKSHOP SOBRE PRODUÇÃO DE SILAGEM NA AMAZÔNIA, 1., 2004, Belém. Anais... Belém: UFRA, 2004. p. 83-100. 